FOR THE RECORD

\section{Failed oversight}

$\mathrm{T}$ he United States Food and Drug Administration's process for approving high-risk class III medical devices is outdated and fails to ensure the safety and effectiveness of such products, according to a report by the highly respected US Government Accountability Office, (www.gao.gov/new.items/d09190.pdf).

The report indicated that since 2003, the FDA allowed 24 different types of class III devices to be cleared as if they were class I and class II devices, such as electrocardiographs, which manufacturers can bring to market without having to provide clinical evidence that they are safe for use.

The 24 included "certain types of hip joints, implanted blood access devices, pedicle screws for certain types of spinal surgeries, [and] dental implants."

\section{No more freebies}

$\mathrm{T}$ he United Kingdom's Royal College of Physicians has joined the growing chorus calling for an end to the "culture" of doctors receiving freebies from the pharmaceutical industry (CMAJ 2008;178[13]:16512 and CMAJ 2008;179[3]:225-6).

A "decoupling" of pharmaceutical industry funding and continuing medical education programs is among the solutions recommended in a College working group report, Innovating for health: Patients, physicians, the pharmaceutical industry and the NHS, released in February (www.rcplondon.ac .uk/pubs/contents/7673804-76c5-4ab389a0-92d44e45edc3.pdf).

With industry having planted "deep roots" in, and funding half of, postgraduate medical education, there is concern that continuing professional development programs are little more than a form of drug promotion, argued the working group in the report.

To redress that, "new ways should be found to reduce the reliance of postgraduate medical education on sponsorship by pharmaceutical companies and the wider biomedical industry." Alternative sources of funding, such as the royal colleges or the federal health ministry, should be sought.

The report also calls for new measures to provide independent assessments of the effectiveness of different prescription drugs, as well as a more principled approach by doctors with respect to receiving payments, gifts, honoraria or hospitality from industry.

\section{Stalled strategy}

$\mathrm{T}$ he much-ballyhooed promise that the National Pharmaceuticals Strategy would reduce the financial burden that prescription medications placed on Canadians was essentially abandoned with the election of Conservative Prime Minister Stephen Harper in 2006, the Health Council of Canada says.

In a progress report on the 2004 strategy - a 9-point action plan to provide more affordable access to drugs that was reached as part of the 2004 intergovernmental Health Accord - the
Health Council bluntly noted the strategy was derailed when the Conservatives were elected.

Progress was being made "but then governments changed, and progress slowed," the Council stated in A Status Report on the National Pharmaceuticals Strategy: A Prescription Unfilled (www.healthcouncilcanada.ca).

Perhaps the most progress was made on the development of a common national drug formulary. But even then, once the provinces and territories reached the point that roughly $90 \%$ of drugs were commonly covered, they indicated that "a common national formulary is no longer needed."

The Health Council wasn't amused. "This would mean that $10 \%$ of medications, which may include newer and/or more expensive medications, are inconsistently offered across the country. Canadians need to know what these medications are, as well as the government's plans to close that $10 \%$ gap." Wayne Kondro, CMAJ

DOI: $10.1503 / \mathrm{cmaj} .090258$

\title{
More news online (www.cmaj.ca)
}

Liability reform: Rising malpractice premiums have prompted calls for tort reforms, like caps on painand-suffering awards. But experts say the solution to endless litigation lies in measures to reduce medical errors. - Janet Rae Brooks, Salt Lake City, Utah

Prayer: After a British nurse was suspended without pay for offering to pray for a patient, the United Kingdom's National Health Service has sketched out when it's acceptable to offer spiritual support. - Mary Helen Spooner, London, England
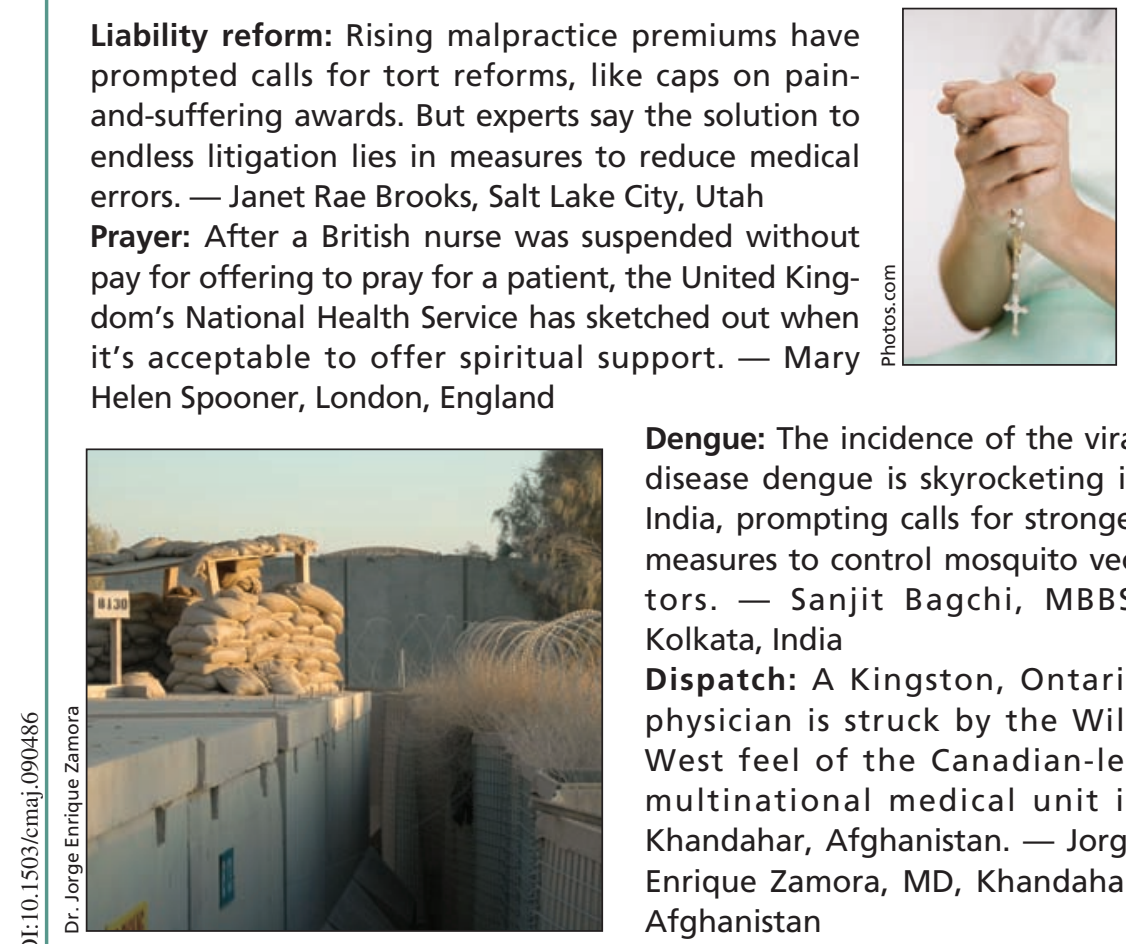

Dengue: The incidence of the viral disease dengue is skyrocketing in India, prompting calls for stronger measures to control mosquito vectors. - Sanjit Bagchi, MBBS, Kolkata, India

Dispatch: A Kingston, Ontario physician is struck by the Wild West feel of the Canadian-led multinational medical unit in Khandahar, Afghanistan. - Jorge Enrique Zamora, MD, Khandahar, Afghanistan 